\title{
A editoração eletrônica de revistas científicas brasileiras: o uso de SEER/OJS
}

\author{
Electronic publishing in Brazilian Scientific Journals: the use of \\ SEER/OJS
}

Ana Gabriela Clipes FERREIRA'

Sônia Elisa CAREGNATO²

\section{RESUMO}

O uso do Sistema Eletrônico de Editoração de Revistas (SEER/OJS) pelos editores de revistas científicas brasileiras é analisado, identificando-se as vantagens e desvantagens e recursos oferecidos pela ferramenta. Verificam-se os motivos que incentivam a utilização desses recursos, assim como o nível de satisfação dos editores que adotaram a ferramenta. Para coletar os dados, foi utilizado um formulário eletrônico, enviado por e-mail para os editores das revistas listadas no site do Instituto Brasileiro de Informação em Ciência e Tecnologia. Obteve-se o retorno de $45,91 \%$ das 98 mensagens eletrônicas enviadas com sucesso. Constata-se que, na opinião dos editores, o número de submissões de artigos aumentou após a implantação do sistema, bem como a busca e recuperação de artigos apresentaram melhorias devido ao recurso da ferramenta de busca. Ainda segundo os editores, o custo com a publicação diminuiu, enquanto o tempo de avaliação dos artigos pelos pareceristas e o tempo para a publicação do periódico não apresentaram mudanças significativas. A navegabilidade foi considerada ótima. Os principais motivos para a adoção do SEER/OJS foram as facilidades de uso e a recomendação da instituição a que está vinculada a revista. O gerenciamento do processo editorial das revistas é o recurso mais utilizado. A avaliação geral da ferramenta foi ótima ou boa. Entre as sugestões para melhorias no sistema, constam a possibilidade de adaptações no leiaute e disponibilização dos artigos em outros formatos e línguas. Sugere-se, para futuros estudos, a avaliação do sistema pelos demais usuários da ferramenta, como os avaliadores, autores e leitores.

Palavras-chave: comunicação científica; editoração científica; periódico científico eletrônico.

\section{ABSTRACT}

The study analyses the use of SEER/OJS by publishers of Brazilian scientific journals. It identifies the advantages and disadvantages, and the resources offered by the tool. It verifies the reasons that encourage the use of SEER and its resources, as well as the level of satisfaction of publishers who have adopted the device. Data was collected by means of an electronic form sent by e-mail to all publishers listed on the IBICT site as users of SEER.

1 Bibliotecária, Associação Nacional de Tecnologia do Ambiente Construído. Projetos InfoHab - Informação e Referência em Habitação (http://www.infohab.org.br/capa.aspx) e Revista Ambiente Construído (http://www.antac.org.br/ambienteconstruido/). E-mail: <anaclipes@gmail.com>.

2 Docente, Faculdade de Biblioteconomia e Comunicação, Programa de Pós-Graduação em Comunicação e Informação, Universidade Federal do Rio Grande do Sul. Rua Ramiro Barcelos, 2705,

Santana, 90035-007, Porto Alegre, RS, Brasil. Correpondencia para/Correspondence to: S.E. CAREGNATO. E-mail: <sonia.caregnato@ufrgs.br>.

Recebido em 31/5/2007 e aceito para publicação em 18/9/2007. 
It got a return rate of $45,91 \%$ of the 98 electronic messages successfully sent. In the publishers' opinion the number of article submission has increased after implementing SEER/OJS, and the search and retrieval performances were improved due to the use of a search tool. According to publishers, publishing costs diminished, but the time necessary for article reviewing and for journals' publication did not present significant improvements. Navigability was considered excellent. The main reasons for adopting SEER/OJS have been the easiness of the use, and the recommendation of the editor's institution. The management of the editorial process was the resource most frequently used. SEER was generally evaluated as excellent or good. Among the suggestions for improvements in the system are the possibility of adaptations in the layout and the availability of articles in other formats and languages. Finally, it suggests the evaluation of the tool by other types of users, such as referees, authors and readers.

Keywords: electronic publishing; scientific communication; electronic journals.

\section{INTRODUÇÃO}

A introdução das Tecnologias de Informação e Comunicação (TICs) trouxe mudanças nos meios eletrônicos e influenciou o comportamento do usuário da informação: não somente o suporte da informação mudou, mas também a maneira pela qual o conhecimento é disseminado e tratado. Os periódicos científicos são um exemplo que ilustra adequadamente essa mudança. Cada vez mais títulos de revistas científicas são disponibilizados no meio eletrônico.

A fim de discutir o periódico eletrônico e sua editoração eletrônica, é necessário salientar alguns aspectos relativos à comunicação científica, a qual pode ser entendida como o resultado dos estudos e pesquisas realizados por grupos de um determinado ramo do saber, concretizado por meio de relatos em publicações.

De acordo com Meadows (1999, p.3), não se pode afirmar "[...] quando foi que se começou a fazer pesquisa científica e, por conseguinte, quando, pela primeira vez, houve comunicação científica." Oficialmente, a resposta a essa questão fica difícil de ser respondida, mas a história da humanidade aponta que séculos antes de Cristo já havia pesquisa, principalmente pelos gregos, que a transmitiam por meio da fala e da escrita (Meadows, 1999).

Até o século XVII, a comunicação científica entre os pesquisadores era feita por meio de cartas, publicações esporádicas de panfletos e livros, não havendo um centro responsável pela transmissão dessas publicações. Devido à informalidade, não havia reconhecimento das informações contidas nessas publicações por outros cientistas (Ziman, 1979).

Com o passar do tempo, a necessidade de preservar o conhecimento gerado por meio da ciência fez com que os pesquisadores passassem a publicar as suas descobertas em canais formais de comunicação. Como a informação científica precisa ser divulgada de forma rápida e com confiabilidade, os periódicos científicos revelaram-se como uma das melhores opções para a publicação de resultados de novos estudos. Com os avanços tecnológicos e a diminuição das barreiras relacionadas à utilização e aceitação dos recursos eletrônicos por autores, leitores e editores, as revistas eletrônicas na Web surgiram como uma alternativa para aumentar a rapidez na disseminação e ampliar a distribuição da informação entre os cientistas, mantendo-se os critérios de qualidade.

Na atualidade observa-se a existência de revistas que migram do formato impresso para o eletrônico e são produzidas das duas maneiras simultaneamente, enquanto outras cessam a versão impressa da publicação e disponibilizam apenas o formato eletrônico e, finalmente, há as que já nascem on-line. A coexistência das versões impressa e eletrônica dos títulos faz surgir as chamadas revistas híbridas (Kling; Spector; Mckim, 2002). Na maioria desses casos, o arquivo oferecido na Web é idêntico àquele publicado na versão impressa, mas há aquelas que diferem da versão impressa, ampliando suas potencialidades a partir da implementação de recursos multimídia. Assim, é de se esperar que sons, imagens, vídeos, além do hipertexto, sejam cada vez utilizados nos periódicos eletrônicos.

Entre as vantagens do periódico eletrônico, podese citar: um número maior de pessoas pode ler e acessar instantaneamente e simultaneamente os artigos; o tempo e custos com o processo impresso podem ser minimizados; as bibliotecas podem dispor de mais espaço nas estantes, pois o grande volume de papel diminuiu de maneira significativa. 
No que concerne ao processo editorial dos periódicos científicos eletrônicos, observa-se que ele é normalmente similar ao dos periódicos impressos: há editor, conselho editorial, revisão por pares, critérios para aceitar ou rejeitar um artigo e formatação. Uma das características desejadas do periódico eletrônico é a maior rapidez em disponibilizar os artigos para o público, tendo em vista que o processo de impressão e distribuição é inexistente na publicação on-line. Todavia, algumas etapas editoriais, como a avaliação por pares, por exemplo, continuam consumindo grande tempo do processo editorial. Apesar da comunicação instantânea por meio da transmissão eletrônica das mensagens, "[...] os atrasos de tempo se devem em grande parte à intervenção humana (isto é, edição, revisão etc.)." (King; Tenopir, 1998, p. 179).

O acesso livre às publicações aumenta o número de leitores atingidos, bem como a rapidez no fornecimento da informação, porém armazenar arquivos em meio eletrônico também implica custos com recursos materiais e humanos, equipamentos, equipe de editoração, manutenção da página e servidores que armazenem os arquivos referentes à publicação. Sem essa estrutura mínima, a revista pode tornar-se inviável.

Para disseminar a informação na Internet, é indispensável a utilização de padrões. De acordo com Márdero Arellano, Ferreira e Caregnato (2005), há cerca de uma década os sistemas eletrônicos de editoração surgiram e se tornaram progressivamente mais úteis com o desenvolvimento dos serviços on-line. Esse tipo de ferramenta trouxe vantagens às publicações eletrônicas, entre elas a redução do tempo consumido e custos administrativos mais baixos. No Brasil, uma ferramenta para a editoração eletrônica de revistas que ganha destaque é o SEER/OJS (Sistema Eletrônico de Editoração de Revistas/Open Journal Systems), do IBICT (Instituto Brasileiro de Informação em Ciência e Tecnologia)

OSEER/OJS é a tradução e adaptação realizada pelo Instituto Brasileiro de Informação em Ciência e Tecnologia (IBICT) do software Open Journal Sistems (OJS), desenvolvido pelo Public Knowledge Project (PKP), da Universidade British Columbia, do Canadá. (IBICT, 2006b). A primeira revista brasileira a utilizar o software na sua versão brasileira foi a Revista Ciência da Informação, em 2004 (Márdero Arellano; Santos; Fonseca, 2005).

Em agosto de 2006, 104 revistas nacionais e 97 internacionais utilizavam o SEER/OJS como ferramenta para publicação na Web (IBICT, 2006a). O Brasil é o país que apresenta o maior número de revistas utilizando essa ferramenta, seguido pelos Estados Unidos e o Canadá. A região brasileira que possui mais publicações padronizadas pelo SEER/OJS é a Região Sul, com $47(45,2 \%)$, seguida pela Sudeste com $43(41,3 \%)$, a Nordeste com 7 (6,7\%), a Centro-Oeste com 5 (4,8\%) e a Norte, com 1 título(1\%) (IBICT, 2006b).

Frente a essa realidade, o presente estudo teve como objetivo geral analisar o uso do SEER/OJS pelos editores das revistas científicas brasileiras que adotaram a ferramenta. Especificamente buscou-se: a) realizar o levantamento das revistas científicas brasileiras que fazem uso do SEER/OJS; b) identificar as vantagens e desvantagens oferecidas pela ferramenta; c) verificar os motivos que levaram à utilização do SEER/OJS; d) verificar a utilização de recursos específicos da ferramenta pelos editores; e) verificar o nível de satisfação dos editores que adotaram a ferramenta.

\section{MÉTODO}

Para atender aos objetivos propostos, optou-se pela pesquisa com os editores das 104 revistas nacionais relacionadas no site do IBICT naquela data, que formaram a população do estudo. $O$ instrumento utilizado para a coleta de dados foi um questionário eletrônico, contendo dez perguntas. Foram enviadas 98 mensagens eletrônicas convidando os editores a participarem da pesquisa, pois das 104 revistas listadas no site do IBICT, uma estava listada duas vezes, três não tinham o endereço para contato com o editor ou responsável e duas constavam como com endereço inexistente. Obteve-se um percentual de retorno de $45,91 \%$ (45 títulos, o que representa $43,26 \%$ dos títulos listados) entre formulários preenchidos e editores que se manifestaram como não aptos a responder. Foram analisados 38 questionários preenchidos $(36,5 \%)$, pois 7 retornaram sem preenchimento, visto terem $o$ editores alegado pouco tempo de uso do sistema.

As questões fechadas (questões 1 a 6 e 9) foram apresentadas utilizando-se da escala Likert. Duas questões permitiam a múltipla escolha (questões 7 e 8) e a última (questão 10) foi totalmente aberta para permitir sugestões, críticas e comentários dos editores participantes da pesquisa.

A primeira solicitação de resposta ao questionário ocorrev em 25 de agosto de 2006, quando 
foi enviado e-mail aos editores. Após dez dias, a mensagem foi reenviada aos que não se haviam manifestado e àqueles cujas mensagens haviam retornado. A data de finalização da coleta de dados ocorreu em 11 de setembro de 2006.

A pesquisa apresentou algumas limitações, entre as quais o pequeno número de questões e a pouca flexibilidade de algumas delas. No entanto o questionário foi assim elaborado a fim de permitir um preenchimento rápido e simples e, conseqüentemente, um grande índice de respostas. Outra limitação foi a existência de endereços eletrônicos desatualizados, o que ocasionou retorno de mensagens. Por fim, a mensagem com o convite de participação foi reenviada apenas uma vez para os que não responderam prontamente, devido ao pouco tempo disponível para coletar os dados e por se acreditar que, pela instantaneidade da comunicação eletrônica, os interessados já teriam respondido no período disponível.

\section{RESULTADOS E DISCUSSÃO}

Das regiões do país representadas na pesquisa, a Região Sul participa com 50\% das respostas, resultado proporcional ao de revistas da região usuárias da ferramenta SEER/OJS: das 104 revistas nacionais listadas, 45,2\% pertencem a ela. A segunda região com mais respondentes foi a Sudeste $(39,5 \%)$, seguida por Centro-Oeste (5,3\%), Nordeste $(2,6 \%)$ e Norte $(2,6 \%)$.

As Ciências Sociais Aplicadas apresentaram $28,9 \%$ de participação, a maior porcentagem do total, representando $27,9 \%$ da população total. Os demais resultados foram: Ciências da Saúde (23,7\%); Ciências Humanas e área Multidisciplinar (13,2\% cada), Ciências Agrárias, Ciências Exatas e da Terra e Lingüística, Letras e Artes (5,3\% cada) e Ciências Biológicas e Engenharias $(2,6 \%)$.

\section{Número de Submissão de Artigos}

Após a implantação do SEER/OJS, o número de artigos submetidos para avaliação aumentou de acordo com 56,75\% dos entrevistados. A informatização do sistema de editoração, segundo Bomfá (2003), minimiza custos decorrentes do envio de artigos pelo correio e agiliza a entrega dos arquivos à edição da revista. Talvez esses sejam os motivos do aumento da submissão verificados pelos respondentes neste estudo, mas é necessário também considerar que as pressões pelo aumento da produção dos professores e pesquisadores das instituições de ensino superior poderiam, por si só, elevar esse índice.

Apenas 2,7\% dos participantes da pesquisa verificaram a diminuição na submissão dos artigos para as revistas que editam e 40,55 \% optaram pela resposta neutra da escala.

Não observar aumento na submissão de artigos para o periódico foi a opção preferida dos editores de revistas eletrônicas que mudaram de outra ferramenta de editoração eletrônica para esta, daqueles que possuem pouco tempo de utilização do SEER/OJS e também dos respondentes que não utilizam ainda todos os recursos da ferramenta.

Esse aumento na submissão de artigos pode ser considerado um aspecto positivo da ferramenta, pois, segundo Bomfá (2003), ele amplia as possibilidades de a revista disseminar a informação científica mais amplamente, contemplando mais autores, sem restrições geográficas. Pode-se acrescentar que o incremento no número de submissões também permite uma melhora na qualidade dos artigos, na medida em que uma seleção mais rigorosa pode ser realizada.

\section{Tempo de Avaliação dos Artigos}

Metade (50\%) dos editores optou pela neutralidade ao responder se houve aumento ou diminuição no tempo dedicado à avaliação dos artigos de sua revista. Há indícios, portanto, de que essa etapa do processo editorial tende a permanecer a mesma, independente do formato do periódico. Embora o envio e recebimento dos artigos por meio eletrônico seja a prática comum, atrasos geralmente ocorrem pela complexidade do trabalho do referee em ler, avaliar e sugerir mudanças para os autores.

Contudo, para 13,89\% dos respondentes, o tempo de avaliação dos artigos diminuiu significativamente e $25 \%$ notaram um bom nível de aumento na velocidade de avaliação. O SEER/OJS, ao gerenciar todas as etapas do processo editorial, facilita a escolha do avaliador e agiliza a comunicação entre ele e a revista. $\mathrm{O}$ avaliador pode acompanhar o processo de 
avaliação dos artigos a ele designados e os autores, acompanhar a tramitação dos seus artigos (Meirelles, 2005). Apenas 2,78\% dos entrevistados apontaram aumento no tempo de avaliação, todavia não foi possível identificar motivos para isso.

\section{Tempo de Publicação da Revista}

Assim como em relação ao tempo de avaliação dos artigos, aqui também a tendência foi optar pela alternativa intermediária da escala. Os principais motivos para isso, segundo os respondentes, foram: o pouco tempo de uso do SEER/OJS, o que não permitiu comparação; a existência de revistas híbridas, cujas provas e impressão interferem no tempo final para a publicação e a existência prévia da revista em meio eletrônico, a qual indicaria que a adoção de uma ferramenta de editoração aparentemente não altera o tempo final de publicação do periódico que sempre foi disponibilizado no meio eletrônico. $O$ item anterior também explica esse resultado: como naquela a maioria respondeu que o tempo para os pareceristas avaliarem os artigos submetidos à revista sofreu pouca ou nenhuma alteração, é razoável inferir que o prazo para a disponibilização da edição seja semelhante ao de antes da adoção da ferramenta de editoração eletrônica. Para 54,04\% dos entrevistados, não houve mudança, enquanto para $27,0 \%$ diminuiv o tempo e para $18,92 \%$ houve aumento.

Os dados obtidos não confirmam o estudo de Bomfá (2003), para quem o tempo de publicação de uma revista eletrônica diminuiu drasticamente, quando comparado com a publicação da revista em formato impresso. Para a autora, cada fascículo de uma revista eletrônica é publicado em três meses em média; já um fascículo de revista impressa necessita, em média, de um ano para ser publicado. Se por um lado alguns dos processos possibilitam menor tempo para a publicação final da edição, outros mantêm prazos semelhantes ao processo editorial impresso.

Os dados, no entanto, são condizentes com aqueles apontados por Kling e Callahan (2003), para quem o processo de publicação eletrônica não diminui substancialmente o tempo de publicação, pois esse é influenciado por forças externas à tecnologia, como o tempo da revisão editorial, tempo de revisão pelos autores e estratégias adotadas pelas revistas para disponibilização dos artigos.

\section{Busca e Recuperação dos Artigos}

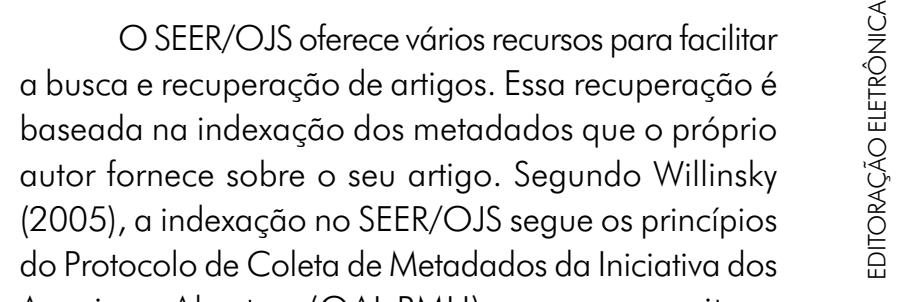
Arquivos Abertos (OAI-PMH), o que permite a recuperação dos artigos disponíveis em diferentes periódicos eletrônicos distribuídos globalmente. Além disso, há uma ferramenta de apoio à pesquisa (RST Research Support Tool), que oferece um sistema interno de busca em recursos de informação abertos na Internet (Márdero Arellano, 2005).

Observou-se que, na opinião dos respondentes, esses recursos provocaram melhorias significativas na busca e recuperação dos artigos. Para 78,94\% dos respondentes, houve melhora, tendo, para 55,26\% deles, melhorado muito. A resposta neutra foi dada por $10,53 \%$ dos respondentes e $10,53 \%$ responderam que piorou, mesmo que não drasticamente. Nenhum dos respondentes apontou uma piora significativa no processo de busca e recuperação dos artigos.

Esse resultado pode ser explicado pelo fato de que o meio eletrônico, sem dúvidas, amplia as opções de busca em periódicos científicos, mas, segundo Kling e Callahan (2003) a implementação delas, por si só, não significa necessariamente que um artigo desejado será recuperado. Para que isso aconteça, os leitores devem utilizar estratégias de busca apropriadas, o que necessita tempo de aprendizado.

\section{Custo de Publicação}

Uma das principais vantagens do periódico eletrônico está relacionada ao custo final da publicação. Quando perguntados sobre isso, 44,74\% dos respondentes afirmaram que houve diminuição significativa com o formato eletrônico, enquanto para outros 15,79\% houve alguma diminuição. A resposta neutra nesse item do instrumento de coletas foi de $31,58 \%$, e o motivo é semelhante ao das questões anteriores: pouco tempo de uso do SEER/OJS e impossibilidade de comparação por ter arevista surgido em formato eletrônico. Para 7,89\% dos pesquisados, houve aumento no custo da publicação: um dos respondentes justifica que "[...] aumenta o custo para 
a implementação, mas diminui no decorrer do processo" (Editor de revista da área de Ciências da Saúde E).

Os dados encontrados estão de acordo com a literatura. Harnad (1995) acredita que a publicação em formato eletrônico é $70 \%$ mais barata do que a publicação em papel, enquanto Morris (2004) prevê uma redução de $20 \%$ na eliminação da publicação impressa. Em uma comparação dos custos de publicação, é necessário considerar, além do preço do papel, de impressão e de distribuição, também os custos de conectividade, de apoio técnico e de arquivamento de longo prazo, entre outros.

Nesta pesquisa, a razão para a diminuição dos custos relatada pela maioria dos editores deve ser atribuída à diminuição de gastos com a impressão (provas parciais e impressão final) e postagem (envio de artigos para avaliação e assinaturas).

\section{Navegabilidade do Sistema}

Periódicos eletrônicos disponibilizados em formatos não padronizados normalmente são de navegação difícil. $\bigcirc$ usuário demora a localizar a informação desejada e normalmente é induzido a dar vários cliques para conseguir obter o que procura. Isso normalmente resulta em uma pesquisa mal sucedida, na qual o usuário não encontra o que procura, ou gera um resultado "acidental". Nesse caso, como a busca não é intuitiva, nem o método de pesquisa é padronizado, a informação é localizada; todavia buscas posteriores não poderão reproduzir os caminhos percorridos. Meirelles (2005) descreve esse tipo de navegação, com muitos links e menus como "um verdadeiro labirinto." O uso de uma ferramenta de editoração como o SEER/OJS promete suprimir várias dessas dificuldades.

Questionados sobre a navegabilidade do sistema, 42,11\% dos respondentes optaram por classificá-la como ótima e 26,32\% como boa. Nenhum dos respondentes considerou a navegação péssima e somente 5,25\% deles a considerou ruim. A neutralidade nessa questão apresenta o percentual de 26,32\%; assim, observa-se que parcela significativa ainda não consegue fazer uma avaliação pontual da navegabilidade do sistema.

Para os leitores das revistas eletrônicas que utilizam a ferramenta SEER/OJS, a navegabilidade melhora com a busca e recuperação dos artigos e com a padronização do leiaute das revistas. Luz (2005) aponta a navegabilidade do sistema como o principal item para o aumento do número de adeptos do SEER/ OJS, porém a percepção dos editores sobre a navegabilidade ainda não pôde ser profundamente avaliada. Alguns dos entrevistados relataram dificuldades em utilizar o processo editorial da ferramenta, mas reconhecem que há limitação pessoal: "Assim a revista é uma ilha de difícil acesso. Até o momento, não percebi grande utilidade. Admito a possibilidade da minha limitação em usar a plataforma." (Editor de revista da área de Ciências da Saúde A).

\section{Motivos para o uso do SEER/OJS como ferramenta de editoração eletrônica}

Em relação aos motivos que levaram à escolha da ferramenta para a editoração eletrônica, 47,4\% dos editores citaram a facilidade em utilizar a ferramenta; $39,5 \%$, a recomendação da instituição a que estão vinculados; $15,58 \%$, a recomendação de outros usuários e 47,4\% apresentaram outros motivos, os quais são listados a seguir. A soma das respostas ultrapassa $100 \%$, tendo em vista a possibilidade de marcar mais de uma alternativa.

As razões adicionais apresentadas foram: baixo custo de publicação e/ou da implantação (oito respondentes); impacto, acessibilidade e visibilidade da revista: (quatro respondentes), apresentação do sistema em encontros e reuniões de editores de revistas científicas (dois respondentes); e, com um respondente cada, adaptação aos módulos existentes anteriormente na revista; padrão OAl e sua relação com softwares livres e forma de arquivamento; facilidades que a ferramenta proporciona; busca de Qualis para a revista; assistência e suporte técnico fornecidos pelo IBICT; e utilização por outras revistas.

\section{Recursos do SEER/OJS}

O SEER apresenta recursos que auxiliam durante todo o processo editorial de publicações eletrônicas. A questão que procurou investigar a utilização desses recursos ofereceu cinco alternativas e um campo aberto para a indicação de outras não apresentadas. 
Os recursos utilizados pelos editores são: gestão do processo editorial, com $35,4 \%$ das respostas; seções, com 17,1\%; estatísticas da revistas e ferramenta RST, com 14,6\% cada; pessoal, com 12,2\%; e outros recursos, com $6,10 \%$, sendo aqui indicada a busca dos avaliadores por área do conhecimento.

Em relação a esses recursos, foram também dadas sugestões e opiniões: "Para a ferramenta de apoio à pesquisa ser mais desenvolvida e utilizada, o editor precisa de um excelente apoio técnico em programação. Além disso, percebo que o público não sabe utilizar o potencial da RST" (Editor de revista da área de Ciências da Saúde D) e "O processo editorial via plataforma é difícil. Os consultores preferem responder via e-mail no lugar de acessar a plataforma. Vejo limitação de não encontrar uma forma de disponibilizar uma ficha de avaliação de artigos". (Editor de revista da área de Ciências da Saúde A).

\section{Avaliação do SEER/OJS}

Na avaliação geral da ferramenta SEER/OJS, $38,71 \%$ dos editores consideram-na como ótima e $48,39 \%$ como boa. Não houve avaliação péssima, mas $6,45 \%$ a avaliaram como ruim. A neutralidade foi baixa $(6,45 \%)$

Esse resultado é coerente com as respostas apresentadas nas questões anteriores. Nenhum dos principais itens pesquisados apresentou resultado consideravelmente ruim. Apesar de algumas dificuldades ainda encontradas pelos editores, o SEER/OJS facilita o processo editorial e, pode-se afirmar, atende ao principal objetivo proposto, que é o de colaborar com os editores na manutenção de publicações científicas periódicas (Márdero Arellano; Santos; Fonseca, 2005).

\section{Visão geral do SEER/OJS pelos editores}

Em espaço aberto do questionário, foram dadas sugestões, relatos de uso da ferramenta e depoimentos de grande satisfação ou total frustração com o sistema ou com a implantação do SEER/OJS. Nela, os editores puderam apontar pontos positivos, negativos e sugestões para melhorias.

Entre as sugestões dadas, constam as que solicitam melhorias na ferramenta, aumentando as alternativas em relação à divulgação da publicação. Três editores acreditam que deveria haver mais flexibilidade na editoração gráfica, como a geração de arquivos em HTML e o uso de Flash na página inicial (Editor de revista da área de Ciências da Saúde F; Editores das revistas da área de Ciências Sociais Aplicadas D e E). Outros dois editores sugerem que o sistema possibilite a publicação de artigos em mais de um idioma (Editores de revista da área Multidisciplinas $\mathrm{B}$ e C). Além disso, segundo eles, a ferramenta não permite a disponibilização de números especiais, já que uma vez selecionada a periodicidade, não é possível inserir números adicionais ou suplementos (Editor de revista da área de Ciências Humanas A). Dois editores, das áreas de Ciências Sociais Aplicadas A e Ciências da Saúde $B$, acreditam que deveria haver melhorias na ferramenta de metadados:

Criar um banco de dados para busca por área de conhecimento; estabelecer a busca por sobrenome de autor; aumentar os campos referentes ao número de telefones (metadados) dos autores; aumentar a opção da classificação de tipos de trabalhos submetidos; recuperar as correspondências emitidas para os autores, etc.; resumir a quantidade de textos (leitura) para a submissão de trabalhos, etc. (Editor de Revista da área de Ciências Sociais Aplicadas A).

O leiaute é considerado de difícil operacionalização pelos entrevistados: é necessário um programador para auxílio, afirma um dos editores da área Multidisciplinar. Por esse motivo, o leiaute do SEER/ OJS é considerado limitado para editores de revistas das áreas de Ciências Sociais Aplicadas F, Ciências da Saúde F, Engenharias A e Multidisciplinar A.

Os editores participantes da pesquisa citaram algumas limitações da ferramenta no processo editorial. Não há como enviar e-mail direto com anexos, por exemplo. Sobre a ferramenta utilizada pelos revisores, um dos respondentes diz que "a parte do sistema de editoração que se relaciona aos revisores não é boa. Seria preciso melhorar o envio dos artigos para os revisores e estabelecer contato entre revisores e autores para tirar dúvidas." (Editor de revista da área das Ciências Humanas A). Essa sugestão, no entanto, não é consensual no trabalho empírico aqui apresentado e nem na literatura da área. Targino e Garcia (2000) alertam sobre os valores subjetivos e tendências dos 
árbitros, que acabam privilegiando correntes teóricas, países, instituições e indivíduos detentores da autoridade da ciência naquele momento. Assim, entende-se que, no atual processo editorial de revistas científicas, não é possível que o avaliador mantenha contato com o autor, tendo em vista que uma das premissas é a de o avaliador e o autor manterem sigilo sobre suas identidades. Do contrário, a idéia de imparcialidade da avaliação não seria válida.

Noutro sentindo, um editor aponta as dificuldades que a revista tem para manter contato com os avaliadores e autores.

\begin{abstract}
O Programa é de difícil entendimento para os pareceristas, principalmente. Dada a dificuldade de encontrar pareceristas disponíveis para a avaliação dos artigos, e ainda com o sistema os pareceristas precisarem fazer os seus cadastros e a dificuldade de se fazer tudo isso, tem sido muito mais difícil esse processo. Além do problema com os pareceristas, os autores também têm dificuldade em enviar os seus artigos dentro das normas e é bastante complicado para o editor realizar pequenas alterações, como a retirada do nome do autor para o envio ao parecerista. $\bigcirc$ instrumento é uma boa idéia que precisa de muitas adaptações para que funcione bem. (Editor de revista da área de Ciências Humanas B).
\end{abstract}

Se, por um lado, há sugestões para que exista maior flexibilidade na ferramenta, há também editores que acreditam que devem ser padronizados outros itens da ferramenta, como as instruções sobre o preenchimento dos dados pelos autores. Para um deles, a fim de evitar que os dados sejam digitados em caixa alta ou caixa baixa indiscriminadamente "Deveria ter uma tela de help para preenchimento" (Editor de revista da área Multidisciplinar A).

Outra limitação que o sistema apresenta são falhas ou "bugs", principalmente no envio de senhas (Editor de revista da área Multidisciplinar E). O problema também é relatado como freqüente por editor da Revista da área das Ciências Humanas C, mas com a ressalva de que são possíveis de serem resolvidas pelo editor.

Outro problema citado é a perda de senha de usuários, tanto de autores como revisores (Editor de revista da área Multidisciplinar D). Um editor do periódico da área das Ciências Sociais Aplicadas B verificou a realização de cinco ou seis cadastros da mesma pessoa com senhas diferentes

Apesar de a navegabilidade ter sido considerada ótima e boa pela maioria dos pesquisados, uma grande parcela optou pela resposta de neutralidade. No formulário, esses editores apresentam as dificuldades que encontram ao usar a ferramenta. Dentre eles, há quem reconheça que não possui habilidades com a tecnologia. Outrossim, fica claro que é indispensável que haja apoio técnico, dentro da instituição, de um profissional especializado em Informática. "O sistema não é totalmente amigável. Poderia ser melhorado em uma versão mais atualizada. Para melhorar o sistema o principal é o treinamento de pessoal, pois a maioria dos editores desconhece o potencial do sistema." (Editor de revista da área de Ciências Exatas e da Terra A).

A resistência no uso de certas tecnologias fica clara em alguns depoimentos enviados na pesquisa: "A grande maioria dos autores simplesmente prefere mandar um e-mail para o editor. De alguma forma é preciso fazer a interface mais amigável e visível" (Editor de revista da área de Ciências Sociais Aplicadas F). Um editor da revista da área de Ciências da Saúde D reconhece o quão difícil é introduzir e aceitar, no meio científico, novos conhecimentos e mudanças inerentes. Maior número de treinamentos oferecidos pelo IBICT é solicitado por dois dos editores das áreas de Ciências Sociais Aplicadas G e Ciências Exatas e da Terra A.

Há duas versões do programa disponíveis na página do IBICT: 1.X e 2.X. Na pesquisa, não foi possível verificar qual a versão mais utilizada pelos participantes. No entanto, um dos respondentes afirmou estar migrando para a versão nova do sistema: "Estaremos estudando a nova versão 2.0 para verificar quais as melhorias que já foram incorporadas. Segundo comentários, a gestão de diversas publicações no mesmo servidor é a mais adequada para a realidade em minimizar custos e adequar padrões" (Editor de revista da área de Ciências Sociais Aplicadas C). Um editor de revista da área de Ciências da Saúde E salienta que está utilizando a versão 2.X e uma das diferenças em relação a versão 1.Xé a possibilidade de gerenciar mais de uma revista.

De modo geral, os editores aproveitaram o campo aberto do questionário para explicitar suas impressões pessoais do sistema. Um deles, da área de Ciências Humanas C, afirma que o sistema poupa muito 
tempo e trabalho. Outro editor afirma que a nomenclatura utilizada é muito específica e técnica, por isso o sistema "[...] não é muito user friendly." (Editor de revista da área de Lingüística, Letras e Artes A).

O leiaute mais flexível é indispensável para alguns tipos de publicação, como as revistas temáticas e de certas áreas do conhecimento, a exemplo das revistas de Comunicação Social. $\bigcirc$ design gráfico, para esse tipo específico de público, é um elemento importante para a leitura dos artigos. Sugere-se, para tal fim, uma página inicial mais individualizada que, por meio de um link, remeta ao conteúdo da revista estruturada de acordo com a ferramenta de editoração eletrônica.

Os artigos também poderiam ser disponibilizados em outro formato, como o HTML. Atualmente, os artigos são oferecidos no formato PDF, que é excelente para o arquivamento em mídias digitais e impressão. Porém, formatos alternativos poderiam agilizar o processo por não demandar o download do documento eletrônico, nem um programa específico para a leitura.

Para finalizar, apresentam-se os relatos de dois editores.

O sistema pode ser melhorado em nível local, basta ter uma equipe de programadores para incrementar o software aberto e fazer as benfeitorias ainda necessárias. A equipe que criou o SEER e o disponibilizou não merece mais trabalho, merece reconhecimento. Porém, para reconhecer é preciso primeiro se informar, trabalhar no software e então, após um período breve de irritação, passar a conhecêlo, o que significa, em última instância, introduzi-lo no processo de trabalho que a divulgação científica exige. (Editor de Revista da área de Ciências da Saúde D).

Como citei anteriormente, embora tudo pareça correto - o SEER/OJS - até então não funciona. A informação que tenho é que demora. Vou esperar até quando sem saber se as informações são corretas? O meu entusiasmo pela plataforma SEER diminui dia-a-dia. A home page [... tem sido mais pesquisada do que a plataforma SEER. (Editor de revista da área de Ciências da Saúde A).

Esses dois relatos demonstram, de forma quase extrema, duas posições claras entre os editores. Há aqueles que acreditam ser a ferramenta uma grande solução para seus problemas de produção de uma revista eletrônica e há aqueles que acreditam que a ferramenta adicionou dificuldades a um processo por si só já complexo. $\bigcirc$ que pôde ser constatado, no entanto, num âmbito mais geral, é a existência de posições menos conceituosas. Se por um lado os editores demonstraram certas dificuldades em alguns itens e sugerem mudanças, outros aspectos do SEER/OJS são avaliados de forma positiva.

\section{CONSIDERAÇÕES FINAIS}

Os resultados apresentados possibilitam ampliar a compreensão sobre um tema de grande importância e atualidade, que é a editoração eletrônica de revistas científicas brasileiras. A perspectiva adotada foi a de levantar a percepção dos editores dessas revistas a fim de contribuir na solução de problemas por eles encontrados e no aperfeiçoamento da ferramenta.

Constatou-se a existência de um nível de satisfação regular. As resistências iniciais em adotar padrões pré-estabelecidos são compreensíveis, como é o caso das tecnologias, por exemplo. No meio científico é necessário ter certo conservadorismo, tendo em vista a necessidade de preservação da informação gerada e disseminada, que é altamente qualificada e confiável.

É necessário que o usuário tenha acesso à informação de maneira simplificada, podendo utilizar todos os recursos que o meio eletrônico proporciona, como as ferramentas de busca e recuperação adequadas, e preservação da informação digital em repositórios. Aos editores, o auxílio de uma ferramenta como a do objeto deste estudo facilita o processo editorial, rico em detalhes específicos em cada uma de suas etapas. Poupar tempo, minimizar custos e ter o controle do envio de artigos para os avaliadores, entre os diversos recursos oferecidos pelo SEER/OJS, contribui para que o editor possa dedicar-se a outras etapas do processo editorial.

Este trabalho levantou apenas a percepção dos editores de periódicos científicos em relação ao uso da ferramenta de editoração eletrônica. Para estudos futuros, sugere-se a avaliação dessa modalidade de editoração entre os outros usuários do meio científico: os avaliadores, autores e, por fim, os leitores das revistas que utilizam o padrão. A análise detalhada do software, tendo caráter mais técnico e feita por pessoal especializado em Ciências da Computação e Informática, também contribuiria para a utilização e melhorias do SEER/OJS. 


\section{REFERÊNCIAS}

BOMFÁ, C.R.Z. Revistas científicas em mídias digitais: critérios e procedimentos. Florianópolis: Visual Books, 2003. 132p.

HARNAD, S. Electronic scholarly publication: quo vadis? Serials Review, v.21, n.1, p.70-72, 1995. Disponível em: <http:// eprints.ecs.soton.ac.uk/archive/00003356/02/harnad95.quo. vadis.html>. Acesso em: 21 jun. 2007.

IBICT. Diretório de revistas brasileiras que utilizam o SEER: região. Disponível em: <http://www.ibict.br/secao.php?cat=SEER/ OJS>. Acesso em: 1 abr. 2006a.

IBICT. Revistas brasileiras que utilizam o SEER/OJS. Disponível em: <http://www.ibict.br/secao.php?cat=SEER/OJS/ Revistas\%20Brasileiras >. Acesso em: 1 abr. 2006b.

KING, D.W.; TENOPIR, C. A publicação de revistas eletrônicas: economia da produção, distribuição e uso. Ciência da informação, v.2, n.27, p.176-182, 1998. Disponível em: <http:// www.ibict.br/cienciadainformacao/include/getdoc. php? id =717 \&article $=398 \&$ mode $=p d f>$. Acesso em: 20 abr. 2007.

KLING, R.; CALLAHAN, E. Electronic journals, the internet, and scholarly communication. In: CRONIN, B; SHAW, D. (Eds)., Annual Review of Information Science and Technology. Medford: InformationToday, 2003. p.127-177.

KLING, R.; SPECTOR, L.; MCKIM, G. Locally controlled scholarly publishing via the Internet: the guide model. The journal of electronic publishing, v.53, n.3, 2002. Disponível em: <http:// www.press.umich.edu/jep/08-01/kling.html>. Acesso em: 25 abr. 2007

LUZ, AR. Arquivística.net: periódico eletrônico em Ciência da Informação e a disseminação do conhecimento científico por meio da Web. Arquivistica.net, v. 1, n. 1, p.65-75, 2005. Disponível em: <http://www.arquivistica.net/ojs/include/getdoc.php?id $=52 \&$ article $=9 \&$ mode $=p d f>$. Acesso em: 25 abr. 2007.

MÁRDERO ARELLANO, M.Á. Sistema aberto de gerenciamento e publicação de periódicos: Repositório Institucional Digital do
IBICT. Disponível em: < https://repositorio.ibict.br/ridi/bitstream/ 123456789/1 15/1/OJS -SEER+2005.ppt>. Acesso em: 15 ago. 2007.

MÁRDERO ARELLANO, M.Á.; FERREIRA, S.M.S.P.; CAREGNATO, S.E. Editoração eletrônica de revistas científicas com suporte do protocolo OAI. In: FERREIRA, S.M.S.P.; TARGINI, M.D.G. Preparação de revistas científicas: teoria e prática. São Paulo: Reichmann \&Autores Editores, 2005. p.195-229.

MÁRDERO ARELLANO, M.Á.; SANTOS, R.; FONSECA, R. SEER: Disseminação de um sistema eletrônico para editoração de revistas científicas no Brasil. Arquivistica.net, v. 1, n.2, p.75-82, 2005. Disponível em: <http://www.arquivistica.net/ojs/include/ getdoc. php? $\mathrm{id}=110 \&$ article $=33 \&$ mode $=p d f>$. Acesso em: 24 abr. 2007.

MEADOWS, A.J. A comunicação cientifica. Brasília: Briquet de Lemos, 1999. 268p.

MEIRELLES, R.F. Implementação da Revista Brasileira de Saúde e Produção Animal no Sistema Eletrônico de Editoração de Revistas - SEER In: ENCONTRO NACIONAL DE CIÊNCIA DA INFORMAÇÃO, 6., 2005, Salvador. Proceedings... Salvador: CINFOR, 2005. Disponível em: <http://www.cinform.ufba.br/ vi_anais/docs/RodrigoMeirelles.pdf> . Acesso em: 24 abr. 2007.

MORRIS, S. Open access: how are publishers reacting? Serials Review, v.30, n.4, p.304-307, 2004.

TARGINO, M.G.; GARCIA, J.C. Ciência brasileira na base de dados do Institute for Scientific Information (ISI). Ciência da Informação, v.29, n. 1, p.103-117, 2000. Disponível em: <http:// www.ibict.br/cienciadainformacao/include/ getdoc. php?id $=614$ \&article $=310 \&$ mode $=p d f>$. Acesso em: 25 abr. 2007.

WILLINSKY, J. Open journal systems: an example of open source software for journal management and publishing. Library HiTech, v.23, n.4, p.504-519, 2005

ZIMAN, J.M. Conhecimento público. Belo Horizonte: Itatiaia, 1979. $164 p$. 